\title{
Omnichannel, da ênfase no Comportamento do Consumidor ao Impacto Organizacional: um levantamento Bibliométrico sob a ótica do Marketing
}

\section{Omnichannel, from emphasis on Consumer Behavior to Organizational Impact: a Bibliometric Survey from the Marketing Perspective}

\author{
Marcelo Lisboa Pereira. Mestrando em Administração. Universidade Federal de Santa Catarina (UFSC) - Brasil. \\ marcelolisboap@hotmail.com \\ Martin de La Martiniere Petroll. Doutor em Administração. Universidade Federal de Santa Catarina (UFSC) - Brasil. \\ martin.petroll@ufsc.br \\ Gabriela Gonçalves Silveira Fiates. Doutora em Engenharia da Produção. Universidade Federal de Santa Catarina (UFSC) - Brasil. \\ gabriela.fiates@ufsc.br
}

\begin{abstract}
RESUMO
Comprar, vender, interagir, integrar, enfim, relacionar-se. As empresas atuam em processo de ampla adaptação, uma vez que as diferentes formas de interação com seus clientes sofrem modificações sistemáticas em função da revolução que a tecnologia, em especial a internet, impõe ao mercado. Entender esta complexidade sobre o aspecto do varejo omnichanne/é o principal objetivo deste trabalho. Com a utilização de estratégias metodológicas da bibliometria e revisão sistemática, este estudo apresenta um levantamento sobre o referido tema, considerando a lente do marketing como principal abordagem. A pesquisa foi realizada em sete bases de dados com intuito de elencar os principais artigos sobre o tema. Os termos pesquisados foram omnichannele sua principal variação omni-channel. As bases utilizadas foram: Google Scholar, Webof Science, Scopus, Periódicos Capes, Scielo, Ebsco Host e Spell. Os principais resultados indicam que os pesquisadores de marketing tratam de omnichannel sob a perspectiva do consumidor (experiências de consumo e a importância da jornada do cliente no varejo omnichannel), das estratégias empresariais adotadas pelas empresas para atuar neste formato de varejo (investimentos em tecnologia para integrar a atuação em diferentes canais) e da interação do marketing com outras áreas organizacionais (integração da área de marketing com outras áreas para atuar neste contexto de varejo). Como conclusão sugere-se as seguintes pesquisas futuras: a) tópicos de entendimento da jornada do cliente; b) as etapas percorridas e, decifrar como as experiências do consumidor podem impactar em novas compras; c) entender como as empresas estão se preparando para lidar com este cenário omnichannel.
\end{abstract}

Palavras-chave: Omnichannel. Comportamento do Consumidor. Marketing. Estratégia.

\begin{abstract}
Buying, selling, interacting, integrating, in short, relating. Companies operate in a process of wide adaptation, as the different forms of interaction with their customers undergo systematic changes due to the revolution that technology, especially the internet, imposes on the market. Understanding the complexity of the omnichannel retail is the main objective of this paper. Using bibliometric methodological strategies and systematic review, this study presents a survey on this topic, from the marketing perspective as the main approach. The research was conducted in seven databases in order to list the main articles on the subject. The search terms were omnichannel and its main omni-channel variation. The bases used were: Google Scholar, Web of Science, Scopus, Capes Periodicals, Scielo, Ebsco Host and Spell. The main results indicate that marketing researchers deal with omnichannel from the consumer's perspective (consumer experiences and the importance of the customer journey in omnichannel retail), the business strategies adopted by companies to operate in this retail format (investments in technology to integrate the performance in different channels) and the interaction of marketing with other organizational areas (integration of marketing with other areas to operate in this retail context). In conclusion, the following topics for future research are suggested: a) understanding the customer journey; b) steps taken followed by consumers and decipher how consumer experiences can impact new purchases; c) understanding how companies are preparing to deal with this omnichannel scenario.
\end{abstract}

Keywords: Omnichannel. Consumer behavior. Marketing. Strategy. 


\section{INTRODUÇÃO}

Grande desafio para as empresas, entender o comportamento de consumo passou a ser tema de grande ambição no contexto organizacional. Diante desta premissa, as empresas procuram entender quais caminhos os consumidores percorrem para obter a melhor experiência de compra, já que são diversas as formas utilizadas por eles para a obtenção de informações sobre os produtos até a decisão de compra. Para tanto, as empresas disponibilizam diferentes canais de acesso aos produtos, sejam estes aplicativos em dispositivos móveis, lojas virtuais, lojas físicas, entre outros. As empresas buscam diferenciar-se no mercado, indicando sua estratégia de atuação. Desta forma, eles podem atuar utilizando apenas um destes canais ou uma variedade deles. Quando optam por ofertar mais de um canal, atuam em estratégias de multichanne/(ou multicanal), que "é o conjunto de atividades envolvidas na venda de mercadorias ou serviços aos consumidores por meio de mais de um canal"(Zhang et al., 2010, p.168). Porém, esta estratégia não apresenta uma preocupação com a interação e integração entre os canais.

Contudo, quando a preocupação passa a ser a integração destes canais, ou seja, uma forma de tornar única a experiência de consumo, já que, independentemente da escolha, o consumidor será cercado das mesmas características de compra nos diferentes canais, a abordagem é omnichannel (ou unicanal). Para Verhoef, Kannan e Inman (2015), omnichannel é a estratégia de varejo que aplica um gerenciamento sinergético dos inúmeros canais disponíveis e dos pontos de contato com o cliente, de modo que a experiência do cliente e o desempenho do canal sejam otimizados.

Desta forma, torna-se necessário um melhor entendimento sobre esta estratégia de varejo, o que serve como uma das justificativas do presente estudo. Para Bell, Gallino e Moreno (2014), os estudos na área de varejo precisam focar no entendimento de questões relacionadas ao comportamento dos clientes, uma vez que eles se tornaram omnichanne/em seus comportamentos e perspectivas. Galipoglu et al. (2018), indicam em suas conclusões ao investigarem o estado da arte sobre omnichannel, que o foco intelectual está incorporado na área de marketing, mesmo assim ainda carece de base teórica sólida, necessitando de mais pesquisas sobre o tema. Corroborando a esta assertiva, o tema em questão é uma das indicações de pesquisa na área de marketing, de acordo com a MSI Research Priorities para o biênio 2018-2020. Além disto, no aspecto gerencial, o estudo indica pontos nos quais as empresas precisam focar, principalmente no entendimento do comportamento do consumidor, apresentado também informações acerca das estratégias empresariais que estão sendo adotadas para atuação no formato de varejo omnichannel. Para completar, dados do mercado indicam que, quase um terço dos brasileiros compram produtos on-line ao menos uma vez por semana, sendo que, quando a compra ocorre via smartphone, os dados indicam que metade dos brasileiros realizam suas compras ao menos uma vez por mês através desta tecnologia (PWC Brasil, 2019). Ainda conforme relatório da PWC (2019), as empresas precisam focar no que eles atribuem ao conceito de retorno sobre a experiência (ROX), para medir o resultado da empresa, o que torna ainda mais importante o estudo sobre varejo omnichannel, uma vez que estes dados possuem amplo impacto nesta estratégia de varejo.

Sendo assim, para melhor entender este contexto, objetiva-se com este estudo, contribuir através de uma atualização do que vem sendo pesquisado sobre o tema, situando as principais abordagens que o cercam. Através de um estudo bibliométrico complementado por uma revisão sistemática, este trabalho proporciona tal atualização, apresentando o que de mais importante vem se estudando sobre omnichannel. Para isto, levantou-se uma amostra de 58 artigos, extraídos de sete diferentes bases de dados, a fim de analisar e entender o que de mais relevante vem sendo pesquisado sobre o tema. Assim o estudo permite entender o conceito de omnichannel, visualizar o contexto em que estão inseridos os estudos desta temática, assim como as principais abordagens pesquisadas. Aspectos metodológicos explicam como os artigos foram identificados e selecionados. Os resultados são sintetizados em um quadro resumo, indicando lacunas teórico-empíricas extraídas dos 58 artigos analisados pelo presente estudo. $O$ estudo limita-se ao fato de abordar o tema apenas sob a ótica de marketing, assim como pela amostra estudada, uma vez que outros estudos sobre o tema não são contemplados aqui. O número de bases pesquisadas também é fator limitante do estudo.

\section{O CONTEXTO OMNICHANNEL}

Com o objetivo de entender o tema omnichannel, primeiro é necessário explicar alguns conceitos centrais de marketing. Diante disto, é importante entender o conceito de canais de marketing. Nesta seção serão abordadas as definições de canais de marketing e omnichannel, para melhor situar o objeto de estudo.

Apesar do foco do trabalho estar situado em omnichannel, também é preciso entender que não são todas as organizações que atuam nesta estratégia de varejo. De acordo com dados do mercado europeu, lojas 
físicas com 79\% e, websites com 73\%, são os canais mais utilizados para geração de vendas, onde a estratégia de varejo omnichanne/ é utilizada por apenas $21 \%$ dos varejistas pesquisados (PWC 2017). Para Mundim e Petroll (2018), a classificação de um varejista ocorre acerca de um continuum, onde em uma das extremidades encontram-se varejistas que atuam em um único canal e, na outra, os varejistas omnichannel, ficando a estratégia multicanal e cross-channe/ como intermediárias neste continuum. Quando a estratégia adotada refere-se a varejistas que atuam em um único canal, estes são classificados como puramente on-line ou puramente off-line, podendo ser diferenciados de acordo com alguns fatores, como por exemplo, quanto a sua abrangência no mercado, uma vez que na estratégia off-line o alcance das empresas em relação aos consumidores é mais limitado do que na plataforma on-line (Otto \& Chung, 2000).

Uma estratégia intermediária adotada pelos varejistas é a de multichannel (ou multicanal). Nesta estratégia, os varejistas ofertam ao consumidor diferentes canais de acesso, porém estes canais não possuem características de integração entre eles. De acordo com Verhoef, Kannan, e Inman (2015), a estratégia multicanal foi impulsionada pelo crescimento dos canais on-line. Desta forma, as empresas entenderam que precisavam estar presentes além dos canais tradicionais.

Nesta visão, Neslin et al. (2006), afirmam que gerir clientes na estratégia multicanal requer preocupação com uma série de atributos como: design, implantação, coordenação e avaliação de canais, através dos quais empresas e clientes interagem com o objetivo de aumentar o valor do cliente. Sendo assim, o processo de gestão organizacional se torna mais complexo, uma vez que, questões relacionadas à forma de atender o consumidor no formato multicanal envolvem não só a área de marketing, mas também a empresa como um todo. Importante ressaltar que nesta estratégia multicanal, o consumidor possui diferentes possibilidades de contato com a organização, porém não há nenhuma interação entre estes pontos, ou seja, cada canal possui autonomia única de iniciar e finalizar o processo de compra junto ao cliente. Caso o cliente opte por mudança de canal, não poderá recuperar a jornada iniciada em outro canal. Para que isto seja possível, a definição apropriada passa a ser a de cross-channel.

ParaBeck e Rygl (2015), cross-channe/é o formato de varejo onde o consumidor tem a liberdade de comprar em uma loja on-line e retirar em uma loja física, ou seja, é uma integração parcial dos canais, haja visto que não há necessidades destes estarem inteiramente integrados para que este processo ocorra.

Mesmo que a missão das empresas já tenha se tornado extremamente complexa na plataforma de atuação multicanal, a estratégia que requer ainda mais atenção e dinâmica organizacional é a do varejo omnichannel. Para Piotrowicz e Cuthbertson (2014), o conceito de omnichannel é percebido como uma evolução do multichannel. De acordo com Carvalho e Campomar (2014), omnichannel pode ser entendido como onipresente ou como aquilo que envolve tudo dentro do processo de distribuição. Nesta visão evolutiva, o omnichanne/surge em uma estratégia ampliada, que vai além de atender os consumidores em diferentes canais. Esta estratégia se fortalece à medida que a linha entre os canais on-line e físicos deixa de existir. Seu caráter integrativo tem por objetivo oferecer uma experiência perfeita ao cliente, independentemente do canal (Piotrowicz \& Cuthbertson, 2014). Nesse sentido, "o varejo omnichannel é um ambiente em que os clientes compram em uma variedade de canais on-line e off-line" (Bell, Gallino, \& Moreno, 2014, p. 45).

Entende-se que tal realidade só foi e é possível, pois a Internet, as diferentes mídias sociais e os dispositivos móveis revolucionaram a experiência do cliente no varejo, uma vez que ele possui diferentes plataformas de pesquisa e compra, a qualquer hora e em qualquer lugar (Hansen \& Sia, 2015).Gao e Su (2016), concluem em seus estudos que os clientes em um ambiente de varejo omnichannel escolhem estrategicamente canais para a compra e o atendimento. O cliente omnichannel é móvel, altamente conectado e adota a tecnologia diariamente em sua vida (Cook, 2014).

Portanto, é importante que as empresas estejam atentas ao comportamento do consumidor neste contexto omnichannel, uma vez que entender estes comportamentos auxilia na implantação das melhores estratégias de marketing.

\section{PROCEDIMENTOS METODOLÓGICOS}

O presente trabalho se apropriou dos princípios metodológicos de Saunders, Lewis, e Thornhill(2009), que enquadram os estudos bibliométricos e revisão sistemática como estratégias de pesquisa: "a bibliometria é uma técnica quantitativa e estatística de medição dos índices de produção e disseminação do conhecimento científico" (Araújo, 2006, p.12). Já a revisão sistemática, utilizada em complemento à bibliometria com o intuito de auxiliar no entendimento dos dados aprofundando sua análise é para Sampaio e Mancini (2007 p.83), "uma forma de pesquisa que utiliza como fonte de dados a literatura sobre determinado tema". Ainda conforme os autores, "as revisões sistemáticas são particularmente úteis para integrar as informações de um conjunto de estudos realizados separadamente" (Sampaio \& Mancini, 2007 p. 84). 
Em função da utilização de duas diferentes estratégias de pesquisa, foi necessária a utilização de uma abordagem mista, pois os dados são trabalhados de forma quantitativa e qualitativa. "A pesquisa de métodos mistos, se concentra em coletar, analisar e misturar dados quantitativos e qualitativos em um único estudo ou uma série de estudos" (Creswell \& Clark, 2013 p.22). Na fase quantitativa, procedimentos estatísticos são utilizados com base na estatística descritiva por meio das fases de coleta, seleção, categorização e comunicação dos dados por meio de tabelas e gráficos (Cunha, 1978). Já na fase qualitativa, a análise de conteúdo, que trata a informação acerca de um roteiro específico em três fases: a) pré-análise, na qual se escolhem os documentos, no caso aqui os artigos; b) exploração do material, traçando objetivos para pesquisa, neste contexto trata da categorização dos artigos e; c) tratamento dos dados e resultados, que liga os resultados obtidos com o corpo teórico do trabalho, neste caso tratando os resultados com a literatura de omnichanne/(Bardin, 1977).

Para a obtenção da amostra, sete bases de dados foram pesquisas com o objetivo de identificar os principais artigos sobre o tema omnichannel. Para tanto, utilizou-se como base o modelo de fluxograma do processo de seleção de estudos de Dybå e Dingsøyr (2008),conforme figura 1, separando a pesquisa em quatro estágios. As bases utilizadas foram: Google Scholar, Webof Science, Scopus, Periódicos Capes, Scielo, Ebsco Host e Spell. A pesquisa foi realizada inicialmente sem aplicação de filtros, justamente para absorver o maior número possível de artigos e, entender em que período o tema começou a ser abordado na literatura, inclusive sem filtro referente a um período específico. Com o mesmo objetivo, o termo omnichanne/foi pesquisado sem associação com qualquer outro termo, variando apenas o seu formato, ou seja, omnichannel e omni-channel. O levantamento dos dados foi realizado no mês de maio de 2019, sendo este o corte final.

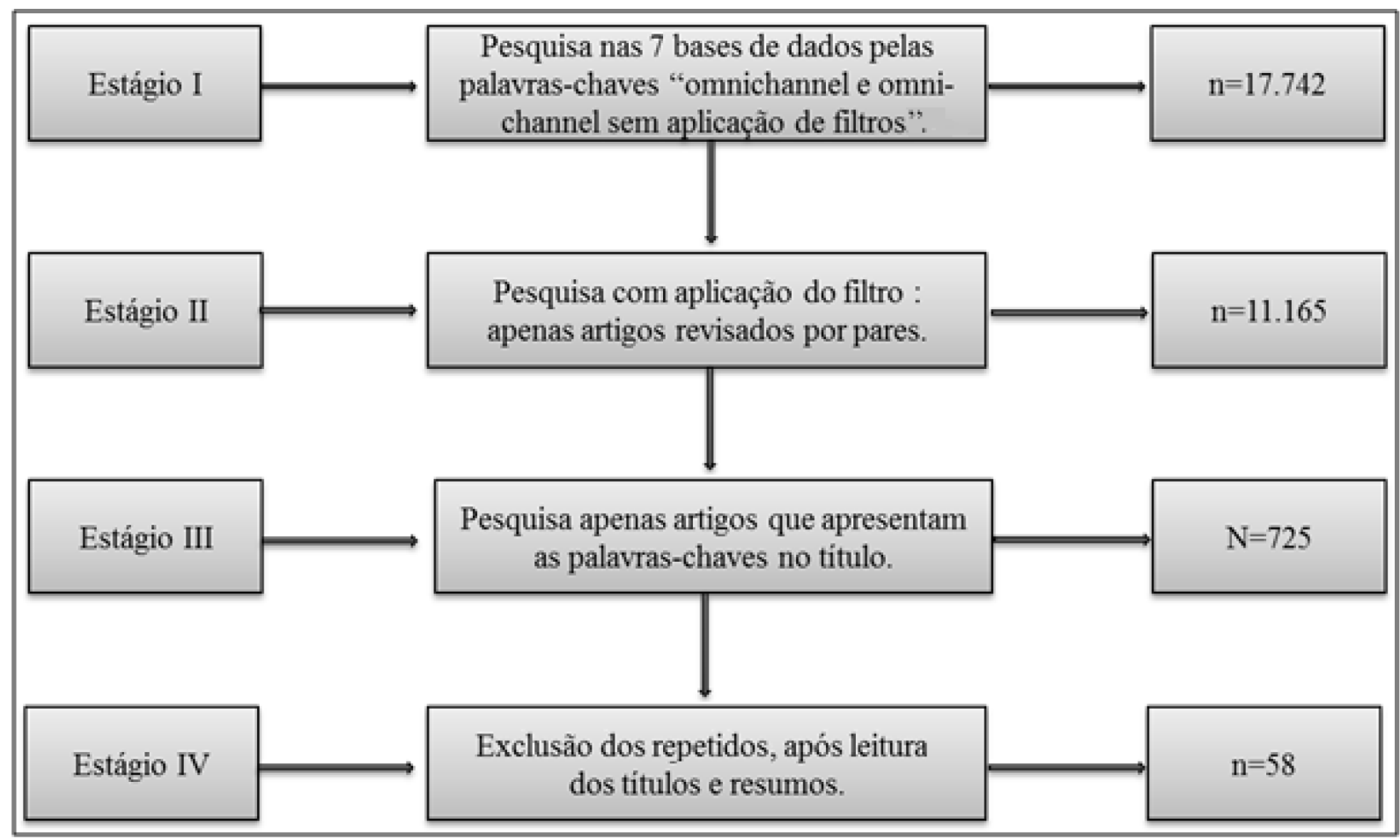

Figura 1: Processo de seleção de estudos.

Fonte: Adaptado de (Dybå \& Dingsøyr, 2008).

\section{ANÁLISE DOS RESULTADOS}

Para esta seção do trabalho, os dados foram analisados em duas etapas, uma quantitativa, que visa apenas à abordagem estatística acerca dos artigos, apresentando dados mais superficiais da amostra, como número de autores, períodos das publicações e principais revistas e, outra qualitativa, onde foi possível uma categorização dos artigos por foco de estudo, o que possibilitou uma análise do conteúdo mais profunda dos artigos pesquisados. 


\subsection{Análise quantitativa dos dados}

Neste tópico serão apresentados os resultados estatísticos acerca da amostra pesquisada. De acordo a evolução temporal, os artigos possuem ocorrência a partir do ano de 2014, onde constam 8 artigos. Os anos de 2015 e 2016 apresentam 7 artigos cada. Com um aumento no número de artigos, o ano de 2017 contempla 10 artigos. Um destaque para o ano de 2018, onde a amostra possui 20 artigos sobre o tema, o que deixa claro a relevância atual dos estudos acerca do omnichannel. Ainda é possível extrair que, apesar do presente trabalho contemplar apenas 5 meses do ano de 2019, já aparecem 6 artigos tratando do tema, indicando que o tema continua em pleno foco de estudo.

Analisando a relação das palavras-chaves dos artigos da amostra, foram identificadas as principais palavras relacionadas ao tema. Dos estudos relacionados ao omnichannel, sendo esta a principal palavra incidente nos artigos, destacam-se os seguintes termos: retailing, customer, channel, experience, consumer, multichannel, marketing, technology, behavioral, cross-channel. Para ilustrar, as palavras mencionadas possuíam de 7 a 42 ocorrências nos artigos. Pelo estudo possuir foco em marketing, a palavra retailing, denominação dada ao conceito de varejo, é a que mais surge após o omnichannel. Questões de cross-channel e multichanne/aparecem, pois são temas que possuem relação direta com omnichannel, que é uma ampliação destes conceitos. Customer, consumer, experiencee behavioral, são temas relacionados a comportamento do consumidor.

Para melhor entender a origem dos conceitos e os principais autores dedicados ao estudo do tema, identificou-se a nacionalidade destes pesquisadores. Destaque neste tópico para os chineses e norteamericanos que juntos somam 46 autores de um total de 133, ou seja, representam 34,59\% do total de autores. O americano David R. Bell, e os argentinos Antonio Moreno e Santiago Gallino, são os autores que mais surgem neste contexto de estudo, onde aparecem com três artigos cada.

Para verificar a relevância dos artigos pesquisados, levantou-se o número de citações deles de acordo com a base de dados Google Scholar. Destacam-se quatro artigos que, somadas suas citações, representam $63,6 \%$ do total de citações dos 58 artigos da amostra. Para perceber a relevância destes artigos, até a data de levantamento dos dados deste trabalho, eles já haviam sido citados 1533 vezes em outros estudos. Em função da amostra possuir 58 artigos e, ser uma tabela relativamente grande, decidiu-se realizar um corte na mesma sob o critério de apresentar no Quadro 1 os artigos com no mínimo 25 citações.

Quadro 1.

Artigos mais citados de acordo com o Google Scholar

\begin{tabular}{|l|c|}
\hline \multicolumn{1}{|c|}{ Título do Artigo } & $\begin{array}{c}\text { Citações } \\
\text { conforme } \\
\text { Google } \\
\text { Scholar }\end{array}$ \\
\hline $\begin{array}{l}\text { From Multi-Channel Retailing to Omni-channel Retailing Introduction to the Special Issue on } \\
\text { Multi-Channel Retailing. }\end{array}$ & 794 \\
\hline $\begin{array}{l}\text { Introduction to the Special Issue Information Technology in Retail: Toward Omnichannel } \\
\text { Retailing. }\end{array}$ & 338 \\
\hline $\begin{array}{l}\text { Categorization of multiple channel retailing in Multi-, Cross-, and Omni-channel Retailing for } \\
\text { retailers and retailing. }\end{array}$ & 221 \\
\hline How to Win in an Omnichannel World. & 180 \\
\hline Hummel's Digital Transformation Toward Omnichannel Retailing: Key Lessons Learned. & 99 \\
\hline Omnichannel Retail Operations with Buy-Off-line-and-Pick-up-in-Store. & 91 \\
\hline $\begin{array}{l}\text { From Cross-channel to "Omnichannel" Retailing: Review of the Literature and Calls for Research. } \\
\text { Omnichannel Customer Behavior: Key Drivers of Technology Acceptance and Use and Their } \\
\text { Effects on Purchase Intention. }\end{array}$ & 68 \\
\hline Omnichannel Retailing: The merging of the off-line and off-line environment & 68 \\
\hline Off-line and off-line information for omnichannel retailing. & 67 \\
\hline Off-line showrooms in omnichannel retail: Demand and operational benefits. & 56 \\
\hline $\begin{array}{l}\text { Customer experience in the omni-channel world and the challenges and opportunities this } \\
\text { presents. }\end{array}$ & 55 \\
\hline
\end{tabular}




\begin{tabular}{|l|c|}
\hline Channel Integration Towards Omnichannel Management: A Literature Review. & 33 \\
\hline Key Factors in Developing Omnichannel Customer Experience with Finnish Retailers. & 30 \\
\hline $\begin{array}{l}\text { Tell me what they are like and I will tell you where they buy. An analysis of omnichannel } \\
\text { consumer behavior. }\end{array}$ & 28 \\
\hline $\begin{array}{l}\text { Product whole life-cycle and omni-channels data convergence oriented enterprise networks } \\
\text { integration in a sensing environment. }\end{array}$ & 27 \\
\hline Cross-channel at Retail and Omni-channel: Challenges for Marketing and Logistics. & 25 \\
\hline
\end{tabular}

Fonte: Elaborado pelos autores (2019).

Sendo assim, neste quadro constam os 17 artigos mais citados, respeitando o critério mencionado. Vale ressaltar que estes 17 artigos selecionados somam 2234 citações e representam 92,6\% do total das citações dos 58 artigos da amostra.

Para que se tenha uma visão da realidade dos locais onde os trabalhos estão sendo publicados, ou seja, as revistas onde os autores escolhem submeter seus artigos, é importante ressaltar que a maioria das publicações são realizadas nos Estados Unidos e no Reino Unido, sendo 48\% das revistas publicadas nestes dois países. Uma das explicações para isso, pode ter relação com o fato destas revistas utilizarem em suas publicações a língua inglesa, o que facilita o alcance dos textos a diferentes locais, uma vez que esta língua é utilizada em todos os continentes do mundo. A revista com maior relevância em relação às publicações é a International Journal of Retail and Distribution Management, na qual constam 3 artigos publicados. Também foi possível verificar a forma como estes artigos estão sendo escritos quanto ao envolvimento de pesquisadores. Constatou-se que $67 \%$ dos artigos são escritos por 2 ou 3 autores.

Como é conhecido, existem diferentes formas de abordar um tema em um artigo. Neste sentido, foi entendido como relevante a questão metodológica dos artigos, ou seja, entender a forma com que estes pesquisadores estão abordando o assunto. Os artigos da amostra foram divididos quanto ao tipo de pesquisa (teórico ou empírico) e, quanto à abordagem: quantitativa, qualitativa ou mista. Dos 58 artigos da amostra, 62\% (36 artigos) são estudos empíricos e 38\% (22 artigos) são teóricos. Das 36 pesquisas empíricas, 28 apresentam abordagem quantitativa, 6 delas apresentam abordagem qualitativa e 2 delas abordagem mista. A próxima seção apresenta a revisão sistemática dos artigos amostrados.

\subsection{Análise Qualitativa dos dados}

Através dos objetivos dos artigos, eles foram classificados em seis categorias. Após a leitura dos artigos, atribuiu-se a eles uma categoria de acordo com seu propósito. Ao final, as categorias foram listadas e, através de uma síntese, chegou-se a seis categorias que serão apresentadas na Tabela 1.

Tabela 1.

\section{Categorização das temáticas}

\begin{tabular}{lcc}
\multicolumn{1}{c}{ Categoria por Temática } & Número de Artigos & $\%$ \\
\hline 1) Comportamento do Consumidor Omnichannel (Experiências e Jornadas) & 25 & 43,10 \\
2) Estratégias de Marketing em Varejo Omnichannel & 16 & 27,59 \\
3) Revisões de Literatura e Indicações Futuras para Omnichannel & 8 & 13,79 \\
4) Diferenças entre canais Multi, Cross e Omnichannel & 4 & 6,9 \\
5) Relação Interdisciplinar do Marketing comoutras disciplinas da Administração & 4 & 6,9 \\
6) Segurança no contexto Omnichannel & 1 & 1,72 \\
\hline \multicolumn{2}{c}{ Total } & 58 \\
\hline
\end{tabular}

Fonte: Elaborado pelos autores (2019).

Sendo assim, a seguir serão apresentadas as principais proposições elencadas sobre cada uma destas categorias, tornando possível o entendimento daquilo que os autores apresentam como principais definições e conceitos,além de entender melhor a forma como o assunto omnichanne/vem sendo estudado.

\subsubsection{Comportamento do Consumidor Omnichannel (Experiências e Jornadas)}

Diante do fato da estratégia de varejo omnichannel atuar fortemente acerca do entendimento do 
comportamento do consumidor, a categoria com o maior número de artigos revela os estudos que exploram esta temática.Os principais resultados constam no Quadro 2.

Quadro 2.

Comportamento do Consumidor Omnichannel (Experiências e Jornadas)

\begin{tabular}{|c|c|c|}
\hline Autor (es) & $\begin{array}{l}\text { Tipo de } \\
\text { Pesquisa }\end{array}$ & Principais Resultados \\
\hline $\begin{array}{l}\text { \& } \\
\text { 2) }\end{array}$ & npírico & $\begin{array}{l}\text { experiência de compra do consumidor sob o varejo omnichanne/possui um } \\
\text { feito positivo nos valores percebidos em relação a produtos e atendimento. }\end{array}$ \\
\hline $\begin{array}{l}\text { (Park \& Lee, } \\
\text { 2017) }\end{array}$ & Empírico & $\begin{array}{l}\text { Idade possui influências significativas no comportamento de escolha do canal, } \\
\text { onde os mais jovens preferem canais móveis e internet. } \\
\text { Os consumidores que usam o canal móvel estão fazendo compras sem } \\
\text { restrições de tempo. }\end{array}$ \\
\hline $\begin{array}{r}\text { Kaza } \\
\text { Aydi }\end{array}$ & Empírico & $\begin{array}{l}\text { s campanhas personalizadas afetam o comportamento de compra dentro do } \\
\text { ontexto omnichannel. }\end{array}$ \\
\hline $\begin{array}{l}\text { (Shen, Li, Sun, } \\
\text { \& Wang, } \\
\text { 2018) }\end{array}$ & Empírico & $\begin{array}{l}\text { Qualidade da integração de canais afeta significativamente a fluência percebida } \\
\text { em diferentes canais. Esse conceito de fluência percebida possui relação com a } \\
\text { capacidade de processamento de informações de um indivíduo, aqui } \\
\text { consumidor. Ou seja, quanto maior a oferta de canais mais capacidade de } \\
\text { processamento de informações o consumidor terá. }\end{array}$ \\
\hline $\begin{array}{c}\text { (Haider, } \\
\text { Zhuang, } \\
\text { AzamHashmi, } \\
\text { \& Ali, 2019) }\end{array}$ & Emp & $\begin{array}{l}\text { Consumidores com hábitos noturnos utilizam mais celulares para pesquisas e } \\
\text { compras; } \\
\text { Consumidores com hábitos diurnos utilizam mais computadores. }\end{array}$ \\
\hline $\begin{array}{l}\text { (Spychalska, } \\
\text { 2017) }\end{array}$ & Teórico & $\begin{array}{l}\text { nalisar as preferências do consumidor; } \\
\text { cias sobre funcionalidade dos canais e valor na relação } \\
\text { lor. }\end{array}$ \\
\hline $\begin{array}{r}(\mathrm{Gu} \\
2 \mathrm{C}\end{array}$ & Empírico & manda geram maior lucro quando vendidos exclusivamente \\
\hline $\begin{array}{r}\text { (Gao 8 } \\
20\end{array}$ & Empírico & $\begin{array}{l}\text { cia das informações possibilitando aos consumidores um } \\
\text { o do produto. }\end{array}$ \\
\hline $\begin{array}{l}\text { (Lee, Chan, } \\
\text { Chong, \& } \\
\text { Thadani, } \\
\text { 2019) }\end{array}$ & Empírico & $\begin{array}{l}\text { A qualidade da integração dos canais influencia positivamente o engajamento } \\
\text { do cliente, a escolha de serviço de canal, a transparência de configuração de } \\
\text { serviço de canal; } \\
\text { Importância a consistência do conteúdo e processo do canal; }\end{array}$ \\
\hline $\begin{array}{r}\text { (Komulair } \\
\text { \& Makkon } \\
\text { 2018) }\end{array}$ & Empírico & $\begin{array}{l}\text { Fatores positivos e negativos estão relacionados à formação de experiências de } \\
\text { clientes em serviços bancários omnichannet: } \\
\text { Positivos: Disponibilidade dos serviços, facilidade de uso do canal; serviços } \\
\text { móveis e complementaridade de canais (uso, por exemplo, do celular para } \\
\text { complementar um atendimento em ambiente físico) } \\
\text { Negativos: Disfunções dos serviços, defeitos técnicos (problemas de } \\
\text { acessibilidade), atrasos no serviço e incompatibilidade na prestação de serviços } \\
\text { entre os bancos. }\end{array}$ \\
\hline (Cook, 2014) & Teórico & $\begin{array}{l}\text { Clientes omnichannel utilizam tecnologia em suas jornadas, como, por } \\
\text { exemplo, smartphones; } \\
\text { Clientes omnichanne/exigem mais aspectos tecnológicos dos varejistas com os } \\
\text { quais fazem negócios; } \\
\text { Clientes omnichannel se tornam muito leais e lucrativos, desde que a } \\
\text { experiência geral seja mantida. }\end{array}$ \\
\hline $\begin{array}{c}\text { (Xu \& Jackson, } \\
\text { 2019) }\end{array}$ & Empírico & $\begin{array}{l}\text { A transparência e a uniformidade dos canais ajudam a reduzir o risco percebido } \\
\text { pelos clientes; }\end{array}$ \\
\hline
\end{tabular}




\begin{tabular}{|c|c|c|}
\hline $\begin{array}{l}\text { (Rajan, } \\
\text { Swaminathan, } \\
\text { \& Pavithra, } \\
\text { 2017) }\end{array}$ & Empírico & $\begin{array}{l}\text { Intenção de compra do consumidor deve ser apoiada por sistemas que tornem } \\
\text { o status do pedido visível para os clientes. }\end{array}$ \\
\hline $\begin{array}{l}\text { (Mosquera, } \\
\text { Ayensa, } \\
\text { Pascual, \& } \\
\text { Borondo, } \\
\text { 2018) }\end{array}$ & Empírico & $\begin{array}{l}\text { Hábito, expectativa de desempenho e a motivação hedônica são os preditores } \\
\text { mais fortes do uso de smartphones nas lojas; } \\
\text { Utilização da loja física como meio de envolver o consumidor e melhorar sua } \\
\text { experiência; } \\
\text { Os consumidores estão à frente dos varejistas em relação à tecnologia. }\end{array}$ \\
\hline $\begin{array}{l}\text { (Peltola, } \\
\text { Vainio, \& } \\
\text { Nieminen, } \\
\text { 2015) }\end{array}$ & Empírico & $\begin{array}{l}\text { Uma boa experiência do cliente omnichanne/reside na união de: } \\
\text { Cultura organizacional, Preços, Operações e comunicações do varejista; } \\
\text { Consumidor omnichannel visto como um caminho promissor para } \\
\text { relacionamentos duradouros. }\end{array}$ \\
\hline $\begin{array}{l}\text { (Reguraman, } \\
\text { 2019) }\end{array}$ & Empírico & $\begin{array}{l}\text { Intenção de compra afetada significativamente por oferta e a qualidade da } \\
\text { operação, conveniência e qualidade do produto. }\end{array}$ \\
\hline $\begin{array}{c}\text { (Ayensa, } \\
\text { Mosquera, \& } \\
\text { Murillo, 2016) }\end{array}$ & Eml & $\begin{array}{l}\text { A intenção do consumidor de comprar em uma loja omnichanne/é influenciada } \\
\text { pela inovação dos varejistas, expectativa de esforço e expectativa de } \\
\text { desempenho dos canais. }\end{array}$ \\
\hline $\begin{array}{l}\text { (Blom, Lange, } \\
\text { \& Hess, 2017) }\end{array}$ & $\mathrm{Emp}$ & $\begin{array}{l}\text { Os varejistas se beneficiam do uso de traços digitais de compras. São as } \\
\text { informações que os clientes deixam nos canais através de seus históricos de } \\
\text { compras e consultas. }\end{array}$ \\
\hline (Kang, & Emp & $\begin{array}{l}\text { Informações dos consumidores Omnichannel, a comparação de preços e a } \\
\text { interação social afetaram positivamente o showrooming (comportamento de } \\
\text { compra em que o consumidor consulta na loja física e compra na internet). } \\
\text { A obtenção de informações, a interação social e a busca de sortimento afetam } \\
\text { positivamente o webrooming (comportamento de compra em que o } \\
\text { consumidor consulta na internet e compra na loja física). }\end{array}$ \\
\hline $\begin{array}{l}\text { (Torrico, } \\
\text { Cabezudo, \& } \\
\text { Martín, 2017) }\end{array}$ & Emp & $\begin{array}{l}\text { Traços pessoais, como impulsividade, influenciam o comportamento do } \\
\text { consumidor omnichannel; } \\
\text { Os compradores impulsivos fazem maior uso de dispositivos móveis; }\end{array}$ \\
\hline $\begin{array}{l}\text { (Zhang, Ren, } \\
\text { Wang, \& He, } \\
\text { 2018) }\end{array}$ & Emp & $\begin{array}{l}\text { ter determinado poder frente } \\
\text { a marca, apresenta respostas } \\
\text { ão de canais. }\end{array}$ \\
\hline $\begin{array}{l}\text { (Hendriyani \& } \\
\text { Chan, 2018) }\end{array}$ & Teórico & $\begin{array}{l}\text { Realizar a jornada do cliente para conquistá-lo. Significa entender os canais que } \\
\text { o consumidor utiliza para interagir com o varejista e, em qual deles ele realiza a } \\
\text { compra. } \\
\text { Varejista precisa ser rápido, criativo e inovador. }\end{array}$ \\
\hline $\begin{array}{l}\text { (Barwitz \& } \\
\text { Maas, 2018) }\end{array}$ & Empírico & $\begin{array}{l}\text { As jornadas dos clientes são inerentemente heterogêneas; } \\
\text { Os clientes tendem a usar vários canais e meios em cada fase da jornada; } \\
\text { Os clientes montam jornadas individuais, aproveitando o grande número de } \\
\text { opções de interação disponíveis. }\end{array}$ \\
\hline (Kang, 2 & Empírico & $\begin{array}{l}\text { Consumidores que utilizam mídias sociais, lojas físicas e dispositivos móveis têm } \\
\text { percepções favoráveis quando consomem através de comportamentos de } \\
\text { showrooming e o webrooming. Isto indica que provavelmente consumam } \\
\text { quando a estratégia do varejista é omnichannel. }\end{array}$ \\
\hline $\begin{array}{c}\text { (Kull \& } \\
\text { Hübner, 2016) }\end{array}$ & Empírico & $\begin{array}{l}\text { Os smartphones podem ser: } \\
\text { Partes dos clientes, condutores de processos cognitivos, Apoiadores digitais e } \\
\text { agentes para impulsos compras por impulso (de acordo com os estudos, os } \\
\text { smartphones são utilizados como canal fundamental, agentes em compras não } \\
\text { planejados, levando a um consumo por impulso). }\end{array}$ \\
\hline
\end{tabular}

Fonte: Elaborado pelos autores (2019).

Tendo por base os resultados abordados nos artigos desta seção, é possível visualizar o grau de 
preocupação por entender o comportamento do consumidor em sua jornada de compra diante o varejo omnichannel. É importante destacar que as jornadas dos clientes são heterogêneas, já que os consumidores utilizam diferentes canais e a qualidade destes canais influencia positivamente em sua jornada. Questões como características pessoais e o grau de empoderamento do consumidor neste formato de varejo também aparecem como fatores importantes de análise. Estudos revelam que na Índia, por exemplo, já existe empresa realizando a jornada do cliente, visando entender esse comportamento (Hendriyani \& Chan 2018).

O uso de dispositivos móveis também aparece como ferramenta de relevante utilização quando o consumidor interage com a empresa, onde a utilização de, por exemplo, smartphones, indicam a forma com que o consumidor interage com as empresas.

Por fim, é importante entender que as pesquisas sobre comportamento do consumidor no varejo omnichannel, abordam e, devem continuar neste sentido, questões de experiências de consumo e jornada do cliente. Para tanto, pesquisas que objetivarem entender a atuação do consumidor em cada ponto de contato durante sua jornada de consumo, poderão contribuir para que empresas melhorem, cada vez mais, estas experiências.

\subsubsection{Estratégias de Marketing em Varejo Omnichannel}

Nesta categoria de análise foram agrupados os artigos que possuem como abordagem omnichannel em uma perspectiva das estratégias organizacionais. Os principais resultados estão dispostos no Quadro 3.

Quadro 3.

Estratégias de Marketing em Varejo Omnichannel

\begin{tabular}{|c|c|c|}
\hline Autor (es) & $\begin{array}{l}\text { Tipo de } \\
\text { Pesquisa }\end{array}$ & Principais Resultados \\
\hline $\begin{array}{l}\text { (Mundim \& } \\
\text { Petroll, 2018) }\end{array}$ & Teórico & $\begin{array}{l}\text { Varejistas puramente físicos precisam adentrar no âmbito off-line, mesmo } \\
\text { que de forma não operacional, através do fornecimento de informações; } \\
\text { Varejistas puramente off-line precisam adentrar o ambiente on-line } \\
\text { permitindo o contato dos consumidores com suas mercadorias antes da } \\
\text { aquisição. }\end{array}$ \\
\hline $\begin{array}{l}\text { (Wollenburg, } \\
\text { Holzapfel, } \\
\text { Hübner, \& } \\
\text { Kuhn, 2018) }\end{array}$ & Empírico & $\begin{array}{l}\text { Os varejistas estão começando a usar seus canais integrados para direcionar } \\
\text { clientes em vários canais gerando maiores vendas e melhorar os custos } \\
\text { operacionais no atendimento ao cliente. }\end{array}$ \\
\hline $\begin{array}{c}\text { (Lee \& Leonas, } \\
\text { 2018) }\end{array}$ & Teórico & consumidores, porque ofereceram \\
\hline (Cao \& Li, & Empírico & $\begin{array}{l}\text { to de integração entre } \\
\text { própria possuem maior }\end{array}$ \\
\hline $\begin{array}{l}\text { (Jaeckel \& Yen, } \\
\text { 2019) }\end{array}$ & Empírico & $\begin{array}{l}\text { rados ainda mais para permitir um } \\
\text { errupto; } \\
\text { do inventário na loja off-line. }\end{array}$ \\
\hline $\begin{array}{c}\text { (Parise \& } \\
\text { Guinan, 2014) }\end{array}$ & Empírico & $\begin{array}{l}\text { diado por tecnologia, o fluxo é o grau em que o usuário } \\
\text { o em vários pontos de contato. Em um ambiente de } \\
\text { iência de usuário é mais agradável. }\end{array}$ \\
\hline $\begin{array}{l}\text { (Bell, } \mathrm{C} \\
\text { Moren }\end{array}$ & Empírico & helé ter uma \\
\hline $\begin{array}{l}\text { (Hansen \& Sia, } \\
\text { 2015) }\end{array}$ & Teórico & $\begin{array}{l}\text { O sucesso da estratégia omnichannel da empresa Hummel, passa pela } \\
\text { contratação estratégica de um novo Executivo para a plataforma digital e } \\
\text { consequentemente da criação de um departamento digital. }\end{array}$ \\
\hline $\begin{array}{l}\text { (Piotrowicz \& } \\
\text { Cuthbertson, } \\
\text { 2014) }\end{array}$ & Teórico & $\begin{array}{l}\text { Os varejistas que desejam implementar uma estratégia omnichanne/podem } \\
\text { precisar se concentrar na inclusão de redes sociais e móveis como novos } \\
\text { canais, personalizar e redesenhar sua rede de cadeia de suprimentos e, } \\
\text { entender os diferentes requisitos do cliente. }\end{array}$ \\
\hline $\begin{array}{l}\text { (Hilken et al., } \\
\text { 2018) }\end{array}$ & Teórico & $\begin{array}{l}\text { Realidade aumentada oferece uma infinidade de oportunidades para } \\
\text { fornecer aos clientes uma jornada omnichanne/perfeita. }\end{array}$ \\
\hline $\begin{array}{l}\text { (Bell, Gallino, \& } \\
\text { Moreno, 2018) }\end{array}$ & rico & $\begin{array}{l}\text { A intervenção off-line é mais eficaz quando ocorre no início da jornada de um } \\
\text { cliente com a marca. }\end{array}$ \\
\hline
\end{tabular}




\begin{tabular}{|c|c|c|}
\hline $\begin{array}{c}\text { (Gao \& Su, } \\
\text { 2016) }\end{array}$ & Empírico & $\begin{array}{l}\text { No varejo omnichanne/ nem todos os produtos que podem ser retirados na } \\
\text { loja; } \\
\text { Especificamente, pode não ser lucrativo implementar a estratégia de comprar } \\
\text { off-linee retirar na loja (Buyon-lineand pick-up store-BOPS) em produtos que } \\
\text { vendem bem nas lojas; } \\
\text { O BOPS permite que os varejistas alcancem novos clientes, mas, para os } \\
\text { clientes existentes, a mudança do preenchimento off-line para o } \\
\text { cumprimento das lojas pode diminuir as margens de lucro. }\end{array}$ \\
\hline (Sarmah, 2015) & Empírico & $\begin{array}{l}\text { Os varejistas devem perceber as lojas físicas como um ativo; } \\
\text { O varejo omnichannel torna-se uma ferramenta para manter os clientes } \\
\text { existentes e adquirir novos; } \\
\text { Os varejistas off-line devem alavancar a crescente digitalização. }\end{array}$ \\
\hline $\begin{array}{c}\text { (Gao\& Su, } \\
\text { 2016) }\end{array}$ & Empírico & $\begin{array}{l}\text { Os showrooms físicos podem levar os varejistas a reduzir o estoque da loja; } \\
\text { Os showrooms virtuais podem aumentar os retornos off-line e prejudicar os } \\
\text { lucros, se induzirem uma migração excessiva dos clientes da loja física para } \\
\text { os canais off-line; }\end{array}$ \\
\hline $\begin{array}{c}\text { (Luiz et al., } \\
\text { 2017) }\end{array}$ & Teórico & $\begin{array}{l}\text { A inovação no varejo passa pela estratégia omnichanne/que tem no seu foco } \\
\text { central a proposição de novas e perfeitas experiências aos clientes pelos } \\
\text { varejistas. }\end{array}$ \\
\hline
\end{tabular}

Fonte: Elaborado pelos autores (2019).

Desta forma, os artigos da amostra indicam como as empresas procuram atuar no mercado, utilizando a estratégia omnichannel. Varejistas puramente físicos precisam também adentrar no âmbito off-line e, varejistas desta última estratégia precisam também, de alguma forma, ampliar o contato com o consumidor através de estratégias físicas. Isto irá possibilitar um aumento das vendas e dos lucros. Quando os canais online são foco de estudo, os resultados demonstram que, nas plataformas digitais, é possível proporcionar melhores experiências ao consumidor, além de visualizar e registrar melhor a jornada do cliente.

Neste contexto de varejo, as lojas físicas também possuem papel fundamental, onde o que poderia ser considerado como uma fonte de custos operacionais, na verdade revela-se um ativo importante no processo omnichannel. Sendo assim, os artigos pesquisados apresentam algumas indicações de pesquisas futuras extremamente relevantes. Estas precisam auxiliar as empresas na identificação dos canais que os consumidores estão utilizando. As indicações apontam também para pesquisas que visam entender quais canais precisam possuir maior atenção e, quais podem deixar de ser utilizados, se for o caso. Estrategicamente, os varejistas precisam entender por onde percorre o consumidor em sua jornada, para implantar corretamente suas ações, aumentando desta forma sua eficiência em relação à integração com o cliente.

\subsubsection{Revisões de Literatura e Indicações Futuras para Omnichannel}

Nesta seção serão apresentadas as principais definições sobre o tema abordado. Artigos com a temática conceitual buscam, através da literatura existente, apresentar a forma com que o tema é tratado conceitualmente. Os artigos desta seção estão dispostos no Quadro 4.

Quadro 4.

Revisões de Literatura e Indicações Futuras para Omnichannel

\begin{tabular}{|c|c|l|}
\hline Autor (es) & $\begin{array}{c}\text { Tipo de } \\
\text { Pesquisa }\end{array}$ & \multicolumn{1}{c|}{ Principais Resultados } \\
\hline $\begin{array}{c}\text { (Mirsch, Lehrer, } \\
\text { \& Jung, 2016) }\end{array}$ & Teórico & $\begin{array}{l}\text { A abordagem omnichannel é uma medida apropriada para satisfazer as } \\
\text { necessidades contemporâneas; } \\
\text { Consumidores são altamente informados e pedem o melhor preço e a melhor } \\
\text { experiência; }\end{array}$ \\
\hline $\begin{array}{c}\text { (Morais, } \\
\text { Sarquis, } \\
\begin{array}{c}\text { Cittadin, \& } \\
\text { Hawerroth, } \\
\text { 2015) }\end{array}\end{array}$ & Teórico & $\begin{array}{l}\text { Principais focos de pesquisa em ambiente omnichanne/são: } \\
\text { Comportamento do consumidor, a tecnologia, logística eintegração de canais } \\
\text { e, experiência de compras; } \\
\text { Criação de valor/vantagem competitiva. }\end{array}$ \\
\hline
\end{tabular}




\begin{tabular}{|c|c|c|}
\hline $\begin{array}{c}\text { (Verhoef, } \\
\text { Kannan \& } \\
\text { Inman, 2015) }\end{array}$ & Teórico & $\begin{array}{l}\text { Empresas e clientes estão usando dispositivos móveis nas lojas; } \\
\text { Em um ambiente omnichannel, fornecer uma experiência perfeita entre os } \\
\text { pontos de contato é considerado importante. }\end{array}$ \\
\hline $\begin{array}{l}\text { (Lazaris \& } \\
\text { Vrechopoulos, } \\
\text { 2014) }\end{array}$ & Teórico & $\begin{array}{l}\text { Estratégia omnichanne/ habilitada por tecnologia afeta fortemente tanto o } \\
\text { consumidor quanto empresas; } \\
\text { Tecnologia afeta as etapas do comportamento de compras. }\end{array}$ \\
\hline $\begin{array}{l}\text { (Chen, } \\
\text { Cheung, \& Tan, } \\
\text { 2018) }\end{array}$ & Teórico & $\begin{array}{l}\text { O varejo omnichannel acentua a interação entre canais e consumidores; } \\
\text { Oferecer uma experiência de compra perfeita; } \\
\text { O gerenciamento da cadeia de suprimentos é um componente vital nos } \\
\text { negócios omnichannel, }\end{array}$ \\
\hline $\begin{array}{c}\text { (Frazer \& } \\
\text { Stiehler, 2014) }\end{array}$ & Teórico & $\begin{array}{l}\text { O objetivo do varejo Omnichanne/é criar uma experiência contínua; } \\
\text { Varejistas devem ser capazes de melhorar a experiência de compra } \\
\text { abordando suas estratégias Omnichannel a partir de uma perspectiva de } \\
\text { marketing experiencial. }\end{array}$ \\
\hline (Briel, 2018) & Empírico & $\begin{array}{l}\text { A concorrência futura no setor de varejo será baseada na experiência holística } \\
\text { do consumidor; } \\
\text { Os consumidores, cada vez mais, determinarão quando e como querem } \\
\text { interagir com os varejistas; } \\
\text { Os varejistas terão de reinventar as lojas usando tecnologias digitais; }\end{array}$ \\
\hline $\begin{array}{l}\text { (Beck \& Rygl, } \\
\text { 2015) } \\
\text { (Guissoni, } \\
\text { 2017) }\end{array}$ & Teórico & $\begin{array}{l}\text { Os consumidores desejam uma experiência consistente entre os múltiplos } \\
\text { pontos de contato em suas interações com as empresas. }\end{array}$ \\
\hline
\end{tabular}

Fonte: Elaborado pelos autores (2019).

De acordo com os resultados encontrados nesta seção, é possível notar que a questão da tecnologia atrelada ao aspecto omnichannel é um dos temas mais abordados. A integração dos canais impacta em investimentos em tecnologia. Aspectos relacionados à experiência de compra do consumidor e seu comportamento neste formato de varejo, possuem grande incidência nos estudos sobre o tema. Constata-se assim, que em função da complexidade da temática, não é simples atuar no varejo omnichannel, pois além de entender a melhor forma de interagir com os consumidores nesta estratégia, as organizações também precisam investir recursos para ofertar a experiência demandada pelo consumidor. Sendo assim, é importante que as pesquisas sobre o tema, direcionem seu foco de estudo para a necessidade de entender a melhor forma de integrar os canais da empresa e, quais canais são realmente necessários e mais eficientes. Entender as reais necessidades e demandas dos consumidores omnichannel, também deve ser lente de pesquisas futuras.

\subsubsection{Diferenças entre canais Multi, Cross e Omnichannel}

Abordagem também importante dentro deste contexto de estudo, a preocupação com as definições apropriadas sobre as estratégias de varejo aparece nos artigos da amostra. Os autores apresentam as definições e características que distinguem as abordagens Multi, Cross-e Omnichannel. O Quadro 5 apresenta os resultados.

Quadro 5.

Diferenças entre canais Multi, Cross e Omnichannel

\begin{tabular}{|c|c|c|}
\hline Autor (es) & $\begin{array}{c}\text { Tipo de } \\
\text { Pesquisa }\end{array}$ & \multicolumn{1}{c|}{ Principais Resultados } \\
\hline $\begin{array}{c}\text { (Beck \& Rygl, } \\
2015)\end{array}$ & Teórico & $\begin{array}{l}\text { Multichanne/ indica que canais coexistem sem a possibilidade de o cliente } \\
\text { acionar a interação, nem a possibilidade de o varejista controlar a integração; } \\
\text { O cliente na estratégia cross-channe/pode acionar interações parciais e/ou o } \\
\text { varejista pode controlar a integração parcial; } \\
\text { No varejo Omnichanne/o cliente pode desencadear interação completa e/ou } \\
\text { o varejista controla integração de todos os canais }\end{array}$ \\
\hline $\begin{array}{c}\text { (Berman \& } \\
\text { Thelen, 2018) }\end{array}$ & Teórico & $\begin{array}{l}\text { No contexto multichanne/o foco é na maximização específica de um canal, } \\
\text { quando a estratégia é baseada em diferenciação; }\end{array}$ \\
\hline
\end{tabular}




\begin{tabular}{|c|c|c|}
\hline & & $\begin{array}{l}\text { O varejista que utiliza estratégia omnichannel, concentra-se na maximização } \\
\text { do desempenho total e os clientes recebem uma mensagem uniforme destes } \\
\text { varejistas }\end{array}$ \\
\hline (Bhalla, 2014) & Teórico & $\begin{array}{l}\text { As organizações precisam ter uma visão holística de todos os pontos de } \\
\text { contato do cliente em todos os canais, para que os clientes, independente do } \\
\text { canal, ainda possam experimentar seus principais momentos de verdade. }\end{array}$ \\
\hline $\begin{array}{c}\text { (Yrjölä, } \\
\text { Saarijärvi, \& } \\
\text { Nummela, } \\
\text { 2018) }\end{array}$ & Teórico & $\begin{array}{l}\text { Os varejistas devem avaliar suas estratégias de múltiplos canais em relação a } \\
\text { suas proposições de valor para o consumidor e, se concentrar em alinhá-las } \\
\text { de acordo com eles. } \\
\text { Interessante notar que o papel do cliente muda em diferentes estratégias de } \\
\text { múltiplos canais. Especificamente, ao comparar estratégias multicanais com } \\
\text { estratégias cross-channe/ou omnichannel, a função do cliente parece mudar } \\
\text { de um destinatário passivo para um participante mais ativo no processo de } \\
\text { compra. }\end{array}$ \\
\hline
\end{tabular}

Fonte: Elaborado pelos autores (2019).

Esta categoria trata das definições e apresenta resultados extremamente importantes para o estudo do varejo omnichannel. Entender este contexto passa, primeiramente, por identificar corretamente a estratégia. De forma resumida, a principal diferenciação entre estas abordagens está condicionada ao grau de interação entre os canais, o que reflete diretamente no consumidor e no varejista. Na estratégia multichannel não há interação/integração e, as estratégias podem ser distintas para diferentes canais. No cross-channel estes elementos são parciais, ou seja, em algum momento da jornada pode haver interação entre os canais, como por exemplo, realizar o pedido na no canal on-line e retirar na loja física. Já no omnichanne/ocorrem de forma total, disponibilizando a mesma experiência independente do canal. Diante disto, as sugestões de pesquisas futuras que emergem destas conclusões, direcionam para estudos sobre o entendimento do comportamento do consumidor em cada uma destas estratégias de varejo, uma vez que estas estão sendo utilizadas por diferentes organizações.

\subsubsection{Relação Interdisciplinar do Marketing com outras disciplinas da Administração}

Quando a organização resolve mudar sua estratégia de atuação no mercado, toda sua estrutura acaba sendo impactada. Sendo assim, para entender a estratégia de varejo omnichannel, também é importante apresentar sua relação com outras as áreas organizacionais. O Quadro 6 apresenta os artigos da amostra que abordam esta questão.

Quadro 6

Relação Interdisciplinar do Marketing com outras disciplinas da Administração

\begin{tabular}{|c|c|c|}
\hline Autor (es) & $\begin{array}{l}\text { Tipo de } \\
\text { Pesquisa }\end{array}$ & Principais Resultados \\
\hline $\begin{array}{l}\text { (Heuchert, } \\
\text { Barann, } \\
\text { Cordes, \& } \\
\text { Becker, 2018) }\end{array}$ & Teórico & $\begin{array}{l}\text { Será criada uma linguagem de modelagem que cobre uma perspectiva de } \\
\text { marketing e técnica que suporte a comunicação interorganizacional; } \\
\text { Ao examinar mais de perto as características sociotécnicas, é necessário } \\
\text { analisar os requisitos de negócios necessários para implementar os serviços } \\
\text { propostos sob sua estratégia, estrutura, cultura, processos. }\end{array}$ \\
\hline $\begin{array}{l}\text { (Carvalho \& } \\
\text { Campomar, } \\
\text { 2014) }\end{array}$ & Teórico & $\begin{array}{l}\text { Para cumprir estas e tantas outras promessas, as atividades de marketing } \\
\text { precisam de organização de processos, implementações em sua gestão, } \\
\text { controles em sua execução, melhorias nos resultados e melhor } \\
\text { aprimoramento dos recursos disponíveis. }\end{array}$ \\
\hline $\begin{array}{l}\text { (Li, Luo, Xie, } \\
\text { Feng, \& Du, } \\
\text { 2015) }\end{array}$ & Empírico & $\begin{array}{l}\text { Computação em nuvem, big data, tecnologias de sensoriamento e novos } \\
\text { modelos de negócios são os processos orientadores e a colaboração de } \\
\text { informações entre empresas é mais complexa e diversificada. }\end{array}$ \\
\hline $\begin{array}{c}\text { (Hansen \& Sia, } \\
\text { 2015) }\end{array}$ & Teórico & $\begin{array}{l}\text { Dados e processos em negócios colaborativos tendem a ser fragmentados. } \\
\text { O armazenamento de dados e os modelos de processo de uma operação } \\
\text { comercial estão dispersos entre várias empresas em rede; } \\
\text { São necessários um perfeito gerenciamento do ciclo de vida de todo o } \\
\text { produto, dos requisitos de clientes, mercados e do marketing omnichannel. }\end{array}$ \\
\hline
\end{tabular}

Fonte: Elaborado pelos autores (2019). 
Esta categoria apresenta os entendimentos dos autores quando o tema omnichanne/ relaciona-se com outras áreas organizacionais. Os resultados em relação a esta categoria apontam a preocupação dos autores acerca da integração do marketing, principalmente com tecnologia da informação e logística. Questões como a forma de administrar a logística neste ambiente omnichannelé um dos grandes desafios da organização, já que esta estratégia impacta diretamente a gestão de estoques e, na forma como são disponibilizados os produtos aos consumidores. Para que o processo organizacional funcione, também é necessário grande investimento em tecnologia da informação. Para que os canais atuem integrados os sistemas devem possuir conexão que permita que, as informações sobre o banco de dados de clientes e produtos possuam as mesmas características em diferentes canais. Essas mudanças necessárias para atuar no varejo omnichannel, afetam a organização, sua estrutura, seus processos e, inclusive pode ter impacto nas questões culturais da empresa. Em pesquisas futuras estudos sobre esses impactos tornam-se importantes para entender as mudanças organizacionais necessárias para atuar sob a estratégia omnichannel.

\subsubsection{Segurança no contexto Omnichannel}

Por fim, porém assunto também importante, o varejo omnichanne/ por possuir um elevado grau tecnológico, requer alguns cuidados, uma vez que atua acerca de diversas informações coletadas, principalmente, na plataforma digital. O quadro 7 apresenta o artigo da amostra que trata desta temática.

Quadro 7.

\section{Segurança no contexto Omnichannel}

\begin{tabular}{|c|c|c|}
\hline Autor (es) & $\begin{array}{l}\text { Tipo de } \\
\text { Pesquisa }\end{array}$ & Principais Resultados \\
\hline $\begin{array}{l}\text { (Wetzlinger, } \\
\text { Auinger, } \\
\text { Kindermann, \& } \\
\text { Schonberger, } \\
\text { 2017) }\end{array}$ & Empírico & $\begin{array}{l}\text { Os resultados mostram que serviços personalizados causam preocupações de } \\
\text { privacidade significativas; } \\
\text { Os consumidores expressaram maiores preocupações em relação aos serviços } \\
\text { digitais na loja de varejo. }\end{array}$ \\
\hline
\end{tabular}

Fonte: Elaborado pelos autores (2019).

De acordo com os resultados encontrados, entende-se ser necessário estar atento a importância que os consumidores empregam aos seus dados. A interação e integração propostas no varejo omnichannel demandam atenção sobre o sigilo e privacidade dos dados dos usuários. A confiança que os usuários empregam sobre as organizações podem trazer benefícios para empresa em termos de resultados. Em função do estudo ter sido direcionado para a área de marketing, apenas um artigo foi relacionado na amostra, porém é importante que pesquisas futuras atuem sobre o entendimento do impacto da confiança no contexto omnichannel. Estudos sobre o grau de confiança atrelados ao aumento ou não dos resultados das vendas no ambiente omnichanne/podem trazer relevantes descobertas quando estudado este formato de varejo.

Após a análise dos dados quantitativos e qualitativos o presente estudo propõe um quadro que propõe lacunas de pesquisa para cada uma das categorias, visando contribuir para pesquisas futuras relacionadas ao tema, apresentadas no quadro 8.

Quadro 8.

Principais Lacunas para pesquisas futuras.

\begin{tabular}{|l|l|}
\hline \multicolumn{1}{|c|}{ Categoria } & \multicolumn{1}{c|}{ Lacuna(s) de Pesquisa } \\
\hline $\begin{array}{l}\text { 1) Comportamento } \\
\text { do Consumidor }\end{array}$ & $\begin{array}{l}\text { - Pesquisas para entender como o empoderamento do consumidor no formato de } \\
\text { varejo omnichanne/ afeta em sua relação com o varejista. Realmente o consumidor } \\
\text { Omnichannel } \\
\text { (Experiências e }\end{array}$ \\
Jornadas) & $\begin{array}{l}\text { - Quando a impulsividade do consumidor é mais evidente em sua jornada, ele já } \\
\text { apresenta essa característica antes da decisão de compra o que pode ser utilizado } \\
\text { pela empresa em seu favor, ou este fator atua somente no momento da compra? }\end{array}$ \\
\hline $\begin{array}{l}\text { 2) Estratégias de } \\
\text { Marketing em Varejo } \\
\text { Omnichannel }\end{array}$ & $\begin{array}{l}\text { - Pesquisas para revelar a forma com que as empresas estão usando os dados da } \\
\text { interação entre ela e o consumidor em suas estratégias. Os dados gerados desta } \\
\text { interação estão realmente sendo operados para gerar diferencial competitivo? Se } \\
\text { sim, de que forma as empresas fazem isto? }\end{array}$ \\
\hline
\end{tabular}




\begin{tabular}{|c|c|}
\hline & $\begin{array}{l}\text { - As funcionalidades ofertadas nos canais digitais para atrair o consumidor até a loja } \\
\text { física, impactam em novas vendas para a empresa? } \\
\text { - Quais as funcionalidades mais utilizadas pelos consumidores e, em quais canais } \\
\text { elas são utilizadas? }\end{array}$ \\
\hline $\begin{array}{l}\text { 3) Revisões de } \\
\text { Literatura e } \\
\text { Indicações Futuras } \\
\text { para Omnichannel }\end{array}$ & $\begin{array}{l}\text { Sendo que a experiência de consumo é de extrema relevância para o estudo de } \\
\text { omnichannel, o importante é entender quais os fatores que mais impactam nesta } \\
\text { demanda do consumidor. Se o consumidor está demandando agora por } \\
\text { experiências, o que as empresas podem fazer para ofertar a melhor experiência. } \\
\text { Identificar os principais fatores que tornam esta realizada possível precisa ser foco } \\
\text { de estudo nesta estratégia de varejo. }\end{array}$ \\
\hline $\begin{array}{l}\text { 4) Diferenças entre } \\
\text { canais Multi, Cross e } \\
\text { Omnichannel }\end{array}$ & $\begin{array}{l}\text { A revisão permitiu identificar que a principal característica para diferenciar a } \\
\text { estratégia de varejo é a interatividade entre os canais. Pesquisas futuras devem } \\
\text { explorar outras características, a fim de formar uma teoria central para estes } \\
\text { conceitos, uma vez que, apesar de grande abordagem, não apresenta um autor } \\
\text { central que seus conceitos são utilizados como base para esta teoria. Mais pesquisas } \\
\text { sobre o tema podem identificar estas outras características e assim diferenciar de } \\
\text { outras formas estes conceitos. }\end{array}$ \\
\hline $\begin{array}{l}\text { 5) Relação } \\
\text { Interdisciplinar do } \\
\text { Marketing com outras } \\
\text { disciplinas da } \\
\text { Administração }\end{array}$ & $\begin{array}{l}\text { De que forma ocorre a integração da empresa para atuar neste formato de varejo? } \\
\text { As empresas estão preparadas, de acordo com o conceito omnichannel? } \\
\text { Pesquisas para identificar as tecnologias necessárias para a atuação neste formato } \\
\text { de varejos podem revelar importantes informações com contribuições gerenciais } \\
\text { para o mercado. De que forma, por exemplo, as empresas estão explorando os dados } \\
\text { gerados através de Big Data? }\end{array}$ \\
\hline $\begin{array}{l}\text { 6) Segurança no } \\
\text { contexto } \\
\text { Omnichannel }\end{array}$ & $\begin{array}{l}\text { Pesquisas com foco nos consumidores para verificar se as empresas estão } \\
\text { repassando informações acerca da segurança de seus dados na interação com a } \\
\text { empresa. } \\
\text { Investigar se o varejista que demonstra possuir infraestrutura de segurança, para } \\
\text { conseguir uma relação de confiança com o consumidor, tendo como consequência } \\
\text { um relacionamento mais duradouro. }\end{array}$ \\
\hline
\end{tabular}

Fonte: Elaborado pelos autores (2019).

\section{CONSIDERAÇÕES FINAIS}

O presente estudo teve por objetivo abordar, através de uma bibliometria, complementado por uma revisão sistemática, o tema omnichanne/ sob a ótica do marketing. É importante entender que o estudo se limita ao fato de ter explorado o tema apenas no contexto de artigos relacionados com a área de marketing, já que a estratégia omnichanne/ também possui influência em outras áreas organizacionais de forma mais específica. Apesar de trazer a importância de outras áreas para o funcionamento desta estratégia, o estudo não possui aprofundamento na atuação de cada uma destas outras áreas. Também se limita pelo número de bases de dados utilizadas no levantamento dos artigos da amostra, uma vez que a amostra selecionada não esgota o escopo total de publicações.

Acerca das principais conclusões, a preocupação dos pesquisadores em entender o comportamento do consumidor nesta modalidade de varejo, buscando decifrara ao longo da jornada do cliente, o seu comportamento nos diferentes pontos de contato disponíveis, surge como ponto mais relevante. Neste ponto, o estudo contribui teoricamente indicando lacunas de pesquisas acerca do comportamento do consumidor, como por exemplo, entender como fatores pessoais de empoderamento e impulsividade atuam na interação do consumidor com a empresa. Desvendar quais os principais canais que o consumidor omnichanne/percorre ao longo de sua jornada, também deve ser fonte de pesquisa, pois direcionará as empresas em relação às principais tecnologias utilizadas pelos consumidores. Neste sentido, futuramente, poderá ser desenvolvido um mapeamento da jornada do consumidor omnichannel, que sirva de base para os estudos.

Gerencialmente, o trabalho contribui para as empresas no sentido de demonstrar as principais estratégias que estão sendo utilizadas pelas empresas no contexto de varejo omnichannel. Empresas que ainda não estão atuando neste formato podem utilizar este estudo para melhor compreender as ações organizacionais quando a intenção é melhorar a interação com os consumidores. Neste sentido, o estudo apresenta questões relacionadas à atuação das empresas nos canais e, o que é necessário apresentar ao consumidor para atraí-lo. Entender como a transparência, a coesão das mensagens e uniformidade do conteúdo dos canais, interfere no comportamento do consumidor, são exemplos de fatores importantes que 
devem ser considerados na relação com o consumidor. O estudo ainda indica como as empresas estão utilizando a loja física para interagir com os consumidores através de estratégias como: comprar online e retirar na loja, ou mesmo, comprar online e enviar para a loja mais conveniente para a retirada. Estes exemplos mostram como as empresas podem inserir-se no ambiente omnichannel.

Sendo assim, percebe-se a importância da implementação correta das estratégias organizacionais. É fundamental para a atuação das empresas neste ambiente, investimentos em tecnologia da informação, atenção especial aos aspectos logísticos e da cadeia de suprimentos, assim como a preocupação em tornar este contexto de interação e integração seguro. Estes aspectos interdisciplinares são fatores que também possuem ocorrência no estudo e, indicam onde as empresas precisam focar suas ações. Saber distinguir a estratégia omnichanne/das demais existentes, como multichanne/e cross-channel, também é essencial, uma vez que a estratégia precisa ser clara perante o mercado. Este tópico também foi objeto de análise e, conclui que as empresas precisam deixar evidente a forma de atuação da empresa no mercado. Caso isto não ocorra, pode acarretar problemas de posicionamento de mercado, confundindo o consumidor e, por consequência, gerando problemas para as empresas.

De forma geral, o estudo propõe que pesquisas futuras na área de marketing deverão abordar questões que venham a ajudar no entendimento do comportamento do consumidor durante sua jornada de compra, principalmente através de estudos acerca dos fatores que impactam o consumidor durante esta jornada, já que entender a forma como ele interage com a empresa em cada ponto de contato é essencial. Isto pode revelar informações determinantes para o sucesso empresarial neste formato de varejo. Tais revelações irão auxiliar na implementação das melhores e mais efetivas estratégias organizacionais para atuar neste ambiente tão complexo e desafiador.

\section{REFERÊNCIAS}

Beck, N., \& Rygl, D. (2015). Categorization of multiple channel retailing in Multi-, Cross-, and Omni-Channel Retailing for retailers and retailing. Journal of Retailing And Consumer Services, 27, p. 170-178. https://doi.org/10.1016/j.jretconser.2015.08.001

Bell, B. D. R., Gallino, S., \& Moreno, A. (2014). How to Win in an Omnichannel World How to Win in an Omnichannel World. MIT Sloan Management Review, Fall. Disponível em: https://sloanreview.mit.edu/article/how-to-win-in-an-omnichannel-world/

Bell, D. R., Gallino, S., \& Moreno, A. (2018). Off-line Experiences and Value Creation in Omnichanne/Retail. SSRN Electronic Journal, p. 1-13. Disponível em: https://doi.org/10.2139/ssrn.3260742

Berman, B., \& Thelen, S. (2018). Planning and implementing an effective omnichanne/marketing program. International Journal of Retail \& Distribution Management, 46(7), 598-614.

Bhalla, R. (2014). The omni-channel customer experience : Driving engagement. Journal of Digital \& Social Media Marketing, 1(4), p. 365-372. Disponível em: https://www.ingentaconnect.com/content/hsp/jdsmm/2014/00000001/00000004/art00008

Cao, L., \& Li, L. (2018). Determinants of Retailers' Cross-channel Integration: An Innovation Diffusion Perspective on Omni-channel Retailing. Journal of Interactive Marketing, 44, 1-16.

Carvalho, J. L. G. de, \& Campomar, M. C. (2014). Multichannel at retail and omni-channel: Challenges for Marketing and Logistics. Business and Management Review, 100(8643), 1703-1755. Disponível emhttp://citeseerx.ist.psu.edu/viewdoc/download?doi=10.1.1.663.4708\&rep=rep1\&type=pdf

Chen, Y., Cheung, C. M. K., \& Tan, C. W. (2018). Omnichanne/business research: Opportunities and challenges. Decision Support Systems, 109, 1-4. Disponível em: https://doi.org/10.1016/j.dss.2018.03.007

Cook, G. (2014). Customer experience in the omni-channel world and the challenges and opportunities this presents. Journal of Direct, Data and Digital Marketing Practice, 15(4), 262-266. Disponível em: https://link.springer.com/article/10.1057/dddmp.2014.16

Creswell, J. W., \& Clark, V. L. P. (2013). Pesquisa de Métodos Mistos. Porto Alegre: Penso.

Cunha, S. E. da. (1978). Estatística descritiva: na psicologia e educação. São Paulo: Forense.

Dybå, T., \& Dingsøyr, T. (2008). Strength of Evidence in Systematic Reviews in Software Engineering. ESEM'08: Proceedings of the 2008 ACM-IEEE International Symposium on Empirical Software Engineering and Measurement, (7465), 178-187. Disponível em: https://doi.org/10.1145/1414004.1414034

Frazer, M., \& Stiehler, B. E. (2014). Omnichanne/ retailing: The merging of the on-line and off-line environment. Global Conference on Business \& Finance Proceedings, 9(1), 655. Institute for Business \& Finance Research.

Gao, F., \& Su, X. (2016a). Omnichanne/Retail Operations with Buy-On-line-and-Pick-up-in-Store. Management Science, (June), 0-15. 
Gao, F., \& Su, X. (2016b). On-line and Off-line Information for Omnichanne/Retailing. Ssrn, (November). https://doi.org/10.2139/ssrn.2796566

Galipoglu, E., Kotzab, H., Teller, C., Yumurtaci Hüseyinoglu, I. Ö., \& Pöppelbuß, J. (2018). Omni-channel retailing research-state of the art and intellectual foundation. International Journal of Physical Distribution \& Logistics Management, 48(4), 365-390.

Hansen, R., \& Sia, S. K. (2015). Hummel's Digital Transformation Toward Omnichanne/Retailing: Key Lessons Learned. MIS Quarterly Executive, 14(2), 51-66.

Hendriyani, C., \& Chan, P. A. (2018). Understanding the New Millennial Customer Path in the Era of OmniChannel Marketing in Indonesia. Review of Integrative Business and Economics Research, 7, 359.

Heuchert, M., Barann, B., Cordes, A.-K., \& Becker, J. (2018). An IS perspective on omni-channel management along the customer journey: Development of an entity-relationship-model and a linkage concept. MKWI 2018 - Multikonferenz Wirtschaftsinformatik, 2018-March, 435-446.

Hilken, T., Heller, J., Chylinski, M., Keeling, D. I., Mahr, D., \& de Ruyter, K. (2018). Making omnichanne/an augmented reality: the current and future state of the art. Journal of Research in Interactive Marketing, 12(4), 509-523. Disponível em: https://doi.org/10.1108/JRIM-01-2018-0023

Jaeckel, B., Yen Y. (2019). How a Thought-out Omni-Channel Strategy can help the German Coffee Retailer to Stay Ahead of its Competition: A case of Tchibo. International Journal of Business Management and Economic Research, 10(1), 2019, p. 1526-1533.

Lazaris, C., \& Vrechopoulos, A. (2014). FromMultichannelto"Omnichannel"Retailing: ReviewoftheLiteratureandCallsforResearch. (June). Disponível em: https://doi.org/10.13140/2.1.1802.4967

Lee, H., \& Leonas, K. K. (2018). Consumer Experiences, the Key to Surviving in an Omni-channel Environment: Use of Virtual Technology. Journal of Textile \& Apparel Technology \& Management, 10(3), 1-23. Disponível em: https://ojs.cnr.ncsu.edu/index.php/JTATM/article/view/13353

Li, Q., Luo, H., Xie, P. X., Feng, X. Q., \& Du, R. Y. (2015). Product whole life-cycle and omni-channels data convergence oriented enterprise networks integration in a sensing environment. Computers in Industry, 70, 23-45. Disponível em: https://doi.org/10.1016/j.compind.2015.01.011

Mirsch, T., Lehrer, C., \& Jung, R. (2016). Channel integration towards omnichannel management: a literature review.Pacific Asia Conference on Information Systems Proceedings... 2016. Disponível em: http://aisel.aisnet.org/cgi/viewcontent.cgi?article=1289\&context=pacis2016

Morais, A. S. A. de, Sarquis, A. B., Cittadin, J., \& Hawerroth, M. (2015). Evidenciação da produção científica sobre o tema omnichannel. análise bibliométrica até 2015. CLAV 2016 9th Latin American Retail Conference.

Mundim, M. A. B., \& Petrol, M. D. L. M. (2018). Busca de Informações e Apresentação dos Produtos no Ambiente de Varejo Omnichannel: Estratégias para Varejistas Puramente On-line, Puramente Físicos e Multicanal. Revista Administração Em Diálogo - RAD, 20(2), 123. Disponível em: https://doi.org/10.23925/2178-0080.2017v20i2.35769

Neslin, S. A., Grewal, D., Leghorn, R., Shankar, V., Teerling, M. L., Thomas, J. S., \& Verhoef, P. C. (2006). Challenges and opportunities in multichannel customer management. Journal of Service Research, 9(2), 95-112. Disponível em: https://doi.org/10.1177/1094670506293559

Otto, Q. B., \& Chung, J. R. (2000). A Framework for Cyber-Enhanced Retailing: Integrating E-Commerce Retailing with Brick-and-Mortar Retailing. Electronic Markets, 10(3), 185-191. Disponível em: https://doi.org/10.1080/10196780050177099

Parise, S., \& Guinan, P. J. (2014). How Can Small Businesses Omni-Channel Customer Experience? (Interactive Paper). 34(11).

Piotrowicz, W., \& Cuthbertson, R. (2014). Introduction to the Special Issue Information Technology in Retail: Toward Omnichanne/Retailing. International Journal of Electronic Commerce, 18(4), 5-16. Disponível em: https://doi.org/10.2753/JEC1086-4415180400

Sampaio, R. F., \& Mancini, M. C. (2007). Estudos de Revisão Sistemática: um guia para síntese criteriosa da evidência científica. Rev. Bras. Fisioter., São Carlos, v. 11, n. 1, p. 83-89.

Sarmah, T. (2015). Omni - Channel Retailing : the Opulent Blend. Journal of Arts, Science \& Commerce, V/(3), $1-10$.

Saunders, M., Lewis, P., \& Thornhill, A. (2009). Research methods for business students (5th ed.). Harlow (Essex): Pearson.

Verhoef, P. C., Kannan, P. K., \& Inman, J. J. (2015). From Multi-Channel Retailing to Omni-Channel Retailing. Introduction to the Special Issue on Multi-Channel Retailing. Journal of Retailing, 91(2), 174-181. Disponível em: https://doi.org/10.1016/j.jretai.2015.02.005

Von Briel, F. (2018). The future of omnichanne/retail: A four-stage Delphi study. Technological Forecasting 
and Social Change, 132, 217-229.

Wetzlinger, W., Auinger, A., Kindermann, H., \& Sch, W. (2017). HCl in Business, Government and Organizations. Supporting Business. 10294, 114-129. Disponível em: https://doi.org/10.1007/978-3-319-58484-3

Wollenburg, J., Holzapfel, A., Hübner, A., \& Kuhn, H. (2018). Configuring retail fulfillment processes for omnichannel customer steering. International Journal of Electronic Commerce, 22(4), 540-575.

Yrjölä, M., Saarijärvi, H., \& Nummela, H. (2018). The value propositions of multi-, cross-, and omni-channel retailing. International Journal of Retail and Distribution Management, 46(11-12), 1133-1152. Disponível em: https://doi.org/10.1108/IJRDM-08-2017-0167

Zhang, J., Farris, P. W., Irvin, J. W., Kushwaha, T., Steenburgh, T. J., \& Weitz, B. A. (2010). Crafting integrated multichannel retailing strategies. Journal of Interactive Marketing, 24(2), 168-180. Disponívle em: https://doi.org/10.1016/j.intmar.2010.02.002 